\title{
G protein and MAPK signaling pathways control the ability of Cochliobolus heterostrophus to exploit different carbon sources
}

\author{
Ofir Degani ${ }^{1,2}$ \\ ${ }^{1}$ Tel-Hai College, Upper Galilee, Israel \\ ${ }^{2}$ Migal-Galilee Research Institute, Kiryat Shmona, Israel \\ Email: d-ofir@bezeqint.net, ofird@telhai.ac.il
}

Received 7 December 2013; revised 12 January 2014; accepted 21 January 2014

Copyright (C) 2014 Ofir Degani. This is an open access article distributed under the Creative Commons Attribution License, which permits unrestricted use, distribution, and reproduction in any medium, provided the original work is properly cited. In accordance of the Creative Commons Attribution License all Copyrights (C) 2014 are reserved for SCIRP and the owner of the intellectual property Ofir Degani. All Copyright (C) 2014 are guarded by law and by SCIRP as a guardian.

\section{ABSTRACT}

Phytopathogenic fungi are heterotrophic organisms that excrete a complex array of enzymes for digestion of plant host tissues. Regulation and coordination of extracellular enzyme production, according to growth conditions and fungus nutritional needs, may be controlled by conserved eukaryotic signaling elements such as G-protein subunits and mitogen-activated protein kinase (MAPK). These pathways are known to mediate a complex set of responses in fungi involved in development, reproduction and pathogenicity. Here, we used a series of mutants, deficient in G-protein $\alpha(\mathrm{cga1})$ or/and $\beta$ subunits or in MAPK, to test their contribution to the ability of Cochliobolus heterostrophus to utilize different carbon sources. In saprophytic culture, the G-protein $\alpha$ subunit mutant strains had WT levels of cellulase, pectinase and protease degradation activities, but it grew significantly slower on minimal medium containing maltose. This weakened ability implies an essential role of the CGA1 signaling in some poor nutritional environments. Remarkably, the MAPK null mutant failed to achieve the WT (and cga1) growth rate on cellulose as a sole carbon and did not grow at all for the first seven days of culture. An enzymatic activity test revealed that this strain significantly reduced cellulose extracellular degradation activity when grew on this medium. Deficiency in the MAPK encoding gene also led to reduced ability to grow on pectin, protein sources and maltose as a sole carbon. The evidence presented indicates a significant and nutrient-specific role of the G-protein and MAPK pathways in mediating growth of this fungus in different environments.

\section{KEYWORDS}

Cochliobolus; Carbon Sources; Extracellular Enzymes; G-Protein; MAPK; Plant Pathogen

\section{INTRODUCTION}

Fungal pathogens cause many of the most serious crop diseases. One of the principal reasons for the success of this group is their ability to locate and perceive appropriate host surfaces and then to elaborate specialized infection structures. Enzymes that are either present in the extracellular matrix covering germ tubes or spores, or released from these structures, may contribute to adhesion and preparation of the infection court (reviewed by [1]). Enzymes are manufactured close to the hyphal tip. Some are packaged in vesicles associated with the Golgi and then delivered to the hyphal tip. The contents are released at the tip and diffuse through the wall. Some enzymes are excreted actively through the plasma membrane $[2,3]$. Enzymes in the liquid are thought to erode the cuticle [4-7]. Cutinase and esterase activities in the matrix surrounding uredospores have been demonstrated to contribute to spore adhesion to the leaf cuticle [8]. Directly penetrating fungi that do not differentiate appressoria clearly need cell wall-degrading enzymes for penetration. Localized degradation of plant cell wall material, about $0.2 \mu \mathrm{m}$ deep, was observed along the penetration hypha of $U$. vignae. In this area, the density of pectin and xyloglucan epitopes was reduced by about 50\% (H. Xu \& K. Mendgen, unpublished result described in [1]). Culture fluids of isolates of a few Fusarium solani $f$. sp. differing in virulence showed similar polygalacturonase activities, but polygalacturonate lyase activities correlated with virulence [9]. Elucidation of the impor- 
tance of cell wall-degrading enzymes is hampered by their redundancy and variable regulation. Often, several isoforms of a particular enzyme occur, which may be encoded by a single gene [10].

The inductive cue for expression of enzyme-encoding genes is frequently the substrate, or a substrate degradation product. In culture media containing purified plant cell walls or polymers such as pectin, polygalacturonic acid, cellulose, xylans and others, many fungi synthesize an array of enzymes required to degrade these carbon sources. For example, endopolygalacturonase Clpg2 of the bean pathogen Colletotrichum lindemuthianum is induced transcriptionally by pectin in axenic culture and during appressorium formation [11]. Likewise, Trichoderma reesei cellulases are induced in the presence of cellulose or disaccharide sophorose [12,13], and the cutinase gene from Fusarium solani is induced upon contact with the plant cuticular polymer, cutin $[14,15]$. The presence of a single polymer such as polygalacturonic acid is often sufficient to induce a number of different enzymes, e.g., polygalacturonases, pectin and pectate (polygalacturonate) lyases, and pectin methylesterases [1]. In plants, conserved promoter elements of defenserelated genes responsive to pectic fragments have been identified [16]. A similar situation may exist in fungi, such that plant cell wall fragments could activate fungal transcription factors capable of simultaneous induction of a number of genes encoding cell wall-degrading enzymes. In Aspergillus niger, xylan and D-xylose induce activation of transcription regulator $X \ln R$. XlnR not only controls the transcription of xylanolytic and accessory enzyme-encoding genes, but also directs the transcription of endoglucanase- and cellobiohydrolase-encoding genes [17-19].

Differentiation of appressorium and penetration hypha is also accompanied by the secretion of a complex pattern of lytic enzymes (reviewed by [1]). During appressorium formation, several extracellular proteases appear or show specificity for fibrous hydroxyproline-rich proteins. In addition, several cellulolytic enzymes are formed, and a large proportion of the acidic isoforms were found extracellular. When substomatal vesicles are differentiated, four pectin methylesterases are synthesized and secreted. Next, when haustorial mother cells develop and initiate host wall penetration, polygalacturonate lyase becomes detectable.

Cochliobolus spp. form only weakly melanized appressoria, and melanin-deficient mutants of the rice pathogen C. miyabeanus remain infectious [20]. On the other hand, Cochliobolus species produce a large number of cell wall-degrading enzymes that might play an important role in the penetration process [1]. To test this hypothesis, Walton and colleagues performed targeted inactivation of genes of $C$. carbonum encoding cell wall- degrading enzymes such as endo-polygalacturonase, xylanase, exo-beta 1,3-glucanase and cellulase [21-24]. Likewise, in the apple fruit pathogen Glomerella cingulata, a gene coding for a pectin lyase was inactivated [25]. In neither case was the virulence of the resulting mutants affected. However, all mutants retained various degrees of residual enzyme activity, probably due to genes encoding isoforms of the respective enzyme, which were not affected by mutagenesis.

The full expression of these cell wall-degrading enzymes by fungi depends on mechanisms that are associated with the glucose regulation pathway. In many organisms, glucose represses genes whose products are used to metabolize other carbon sources. Work in yeast and filamentous fungi has revealed a mechanism for glucose repression in eukaryotes that is different from that found in bacteria [26]. For example, cellulase genes of $T$. reesei are repressed in the presence of glucose [12]. It has been shown that the carbon catabolite repressor CreA is involved in transcriptional repression of xylanase and arabinase-encoding genes in Aspergillus species [27,28].

Although studies have focused on the extracellular enzymes of phytopathogenic fungi for many years, the role of G-protein or MAPK-associated cascades in regulating extracellular degrading enzyme secretion has been examined in detail only recently. Evidence of the importance of this signaling role includes the involvement of $\mathrm{G} \alpha$ subunits in the induction of a cellobiohydrolase gene from Cryphonectria parasitica [29] and in the secretion of an extracellular protease from Botrytis cinerea [30]. Studies in S. cerevisiae using genome arrays reveal that pheromone signaling via MAPK induces several genes that are known to be induced during filamentous growth, including a hydrolytic enzyme encoded by the PGU1 gene [31,32]. Dawe et al. [33] used a spotted cDNA microarray platform to examine the effect of the absence of $C P G-1$ ( $\triangle \mathrm{G}$-alpha mutant) or $C P G B-1$ ( $\triangle \mathrm{G}$-beta mutant) genes on global transcriptional profiles. They reported that six predicted acid proteases out of a population of 49 proteases were down regulated in both G-protein-deleted mutants. Five other proteases transcripts were changed in abundance in at least one of the tested strains. Previous work demonstrated that chk1 ( $\triangle \mathrm{MAPK})$ modulates the expression of two cellulase genes in $C$. heterostrophus during plant infection [34]. Here, we tested the contribution of the G-protein and MAPK pathways to the ability of Cochliobolus heterostrophus to exploit different carbon sources.

\section{MATERIALS AND METHODS}

\subsection{Strains}

The strains used are listed in Table 1. 
Table 1. Strains used.

\begin{tabular}{|c|c|c|c|}
\hline Strain & Genotype & Reference or source & comments \\
\hline WT C4 & 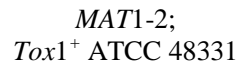 & $\begin{array}{l}\text { (Leach, Lang } \\
\text { et al. 1982) }\end{array}$ & \multirow{2}{*}{ These strains were obtained after six backcrosses and are nearly isogenic. } \\
\hline WT C5 & 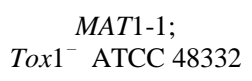 & $\begin{array}{l}\text { (Leach, Lang } \\
\text { et al. 1982) }\end{array}$ & \\
\hline $\operatorname{cga} 1$ & 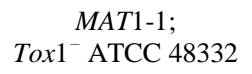 & $\begin{array}{l}\text { (Horwitz, Sharon } \\
\text { et al. 1999) }\end{array}$ & $\begin{array}{l}\text { G-protein } \alpha \text { subunit disrupted mutant, created by insertion of the hygromycin } \\
\text { cassette into the coding region, combined with an 18-bp deletion. }\end{array}$ \\
\hline $\begin{array}{l}\text { C4cga1 } \\
\text { TSC17 }\end{array}$ & 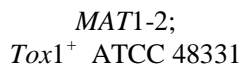 & $\begin{array}{l}\text { (Horwitz, Sharon } \\
\text { et al. 1999) }\end{array}$ & $\begin{array}{l}\text { G-protein } \alpha \text { subunit disrupted mutant, created by complete deletion } \\
\text { of the coding region and insertion of hygromycin cassette. }\end{array}$ \\
\hline $\operatorname{cgb} 1$ & 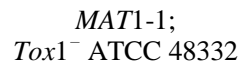 & $\begin{array}{l}\text { (Ganem, Lu } \\
\text { et al. 2004) }\end{array}$ & $\begin{array}{l}\text { G-protein } \beta \text { subunit disrupted mutant, created by insertion of the hygromycin } \\
\text { cassette into the coding region, combined with a } 473 \text { bp deletion. }\end{array}$ \\
\hline $\operatorname{cga} 1 \operatorname{cgb} 1$ & $\begin{array}{c}\text { MAT1-1; } \\
\text {Tox } 1^{-} \text {ATCC } 48332\end{array}$ & (Degani 2013) & $\begin{array}{l}\text { G-protein } \alpha \text { and } \beta \text { subunits double mutant, created by insertion of the Bar cassette } \\
\text { into the CGB1 coding region of cga1 mutant strain, combined with a } 473 \text { bp deletion. }\end{array}$ \\
\hline chk1 & 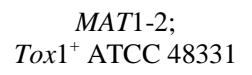 & $\begin{array}{l}\text { (Lev, Sharon } \\
\text { et al. 1999) }\end{array}$ & $\begin{array}{l}\text { MAPK disrupted mutant, created by replacement of the } \\
\text { coding region with the hygromycin resistance cassette. }\end{array}$ \\
\hline$e g 6 f$ & 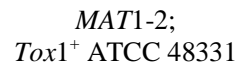 & $\begin{array}{l}\text { (Lev and } \\
\text { Horwitz 2003) }\end{array}$ & $\begin{array}{l}\text { Endoglucanase disrupted mutant, created by insertion of the hygromycin } \\
\text { cassette into the coding region, combined with a partial deletion. }\end{array}$ \\
\hline eg6f chk1 & 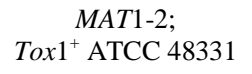 & $\begin{array}{c}\text { (Lev and } \\
\text { Horwitz 2003) }\end{array}$ & $\begin{array}{l}\text { Endoglucanase and MAPK double mutant, created by insertion of the Bar cassette } \\
\text { into the } C H K 1 \text { coding region of eg } 6 f \text { mutant strain, combined with partial deletion. }\end{array}$ \\
\hline$c b h 7 f$ & $\begin{array}{c}\text { MAT1-2; } \\
\text { Tox }^{+} \text {ATCC } 48331\end{array}$ & $\begin{array}{l}\text { (Lev and } \\
\text { Horwitz 2003) }\end{array}$ & $\begin{array}{l}\text { Cellobiohydrolase disrupted mutant, created by insertion of the } \\
\text { hygromycin cassette into the coding region, combined with a partial deletion. }\end{array}$ \\
\hline
\end{tabular}

\subsection{Enzymatic Activity}

In order to determine quantitative differences between WT and signaling deficiency mutant strains, the fungi were cultured on minimal medium plates containing different carbon sources, as described previously [35] unless otherwise indicated. Pectin, gelatin (protein source), carboxymethylcellulose (CMC) or maltose (all obtained from Sigma) were used as a sole carbon source in the minimal medium. The fungi were cultured on these media, in comparison to complete medium (CM) [36] at $30^{\circ} \mathrm{C}$ in continuous white light. Alternatively the cultures were grown on different carbon sources (1\% concentration in the medium) containing in addition $0.1 \%$ maltose at $25^{\circ} \mathrm{C}$ in continuous white light. The colony diameter was measured every 2 - 3 days and samples were used for staining tests.

\subsection{Staining}

The activity of extracellular enzymes of the different strains was estimated qualitatively by staining the culture plates with Congo red (1\% in pure deionized water), which assesses cellulose degradation, or with ruthenium red $(0.2 \%$ in pure deionized water), which assesses pectin degradation, as described previously [35].

\subsection{Carboxymethylcellulose Degrading Enzymes Activity Test}

The Cochliobolus heterostrophus WT strain and signaling deficiency mutants were pre-cultured on CM plates for 5 - 10 days at room temperature under UVA-enriched white light. Six $0.6 \mathrm{~cm}$ diameter culture agar disks were cut from the margins of the colony of each plate and transferred to a $50 \mathrm{ml}$ polycarbonate screw-capped test tube containing $20 \mathrm{ml}$ minimal medium with $0.1 \%$ CMC and $0.1 \%$ maltose. The cultures were incubated diagonally in a rotary shaker at 210 - $230 \mathrm{rpm}$ and at a temperature of $30^{\circ} \mathrm{C}$. The reducing sugar test [37] was then used to estimate CMCase (Carboxymethylcellulose degrading enzymes) activity. Two ml Ependorf tubes containing $200 \mu \mathrm{l} 2.5 \% \mathrm{CMC}$ in $50 \mathrm{mM}$ sodium acetate $\mathrm{pH} 5$ as substrate and $300 \mu \mathrm{l}$ pre-centrifuge extracellular fluid were incubated diagonally in a rotary shaker at $175 \mathrm{rpm}$ and at a temperature of $37^{\circ} \mathrm{C}$ for 2 hours. The tubes were then placed immediately into ice to stop the reaction, and $1 \mathrm{ml}$ of DNS reagent was added to each tube. After mixing, the tubes were boiled in a heating block for 5 minutes, and after cooling to room temperature, absorbance at $550 \mathrm{~nm}$ was measured against a blank containing buffer instead of enzyme. 0 - $2 \mathrm{mg} / \mathrm{ml}$ glucose concentrations were used for the standard curve and assayed in the same way as the samples.

\subsection{Protein}

Protein assay was conducted using Bio-Rad dye reagent according to manufacturer's instructions (microassay procedure). Standard curve was prepared using 0 - 20 $\mu \mathrm{g} / \mathrm{ml}$ albumin (BSA).

\subsection{Biomass}

The mycelium was harvested by filtration through nylon 
mesh and dried in an $80^{\circ} \mathrm{C}$ oven for 16 hours or at $65^{\circ} \mathrm{C}$ for one week on a pre-weighed aluminum foil or Whatman paper. The samples were then kept in desiccators and measured again. The dry biomass was used for calculating the enzymatic activity.

\subsection{Northern Blot Analysis}

Northern blot analysis of EG6F (endoglucanase) gene expression was conducted in WT C4, chk1 and eg6f chk1 strains that were grown on CMC or maltose liquid medium (strains listed in Table 1, conditions as described above). Sample strains from the cultures used for activity assay were tested against EG6F probe, as described earlier [34]. Total RNA was isolated using the phenol-SDS procedure, precipitated with lithium acetate, and denatured with formamide and formaldehyde. Separation was carried out on a formaldehyde-containing agarose gel and blotting onto Hybond $\mathrm{N}$ membrane (Amersham). Hybridizations were carried out at $65^{\circ} \mathrm{C}$, according to [34], with ${ }^{32}$ P-labeled DNA.

\section{RESULTS}

A previous report demonstrated that on detached leaves, the virulence of the G-protein $\alpha$ subunit mutant (cga1) increased, approaching that of WT [38] in comparison to intact leaves infection. Senescing leaves may be closer to a saprophytic substrate, and indeed growth of WT and mutant is quite similar in saprophytic culture. It may be assumed that senescing leaves undergo slow decomposition that facilitates the penetration of the pathogen through the cell wall barriers. We therefore tested whether signaling mutants and WT strains differ in their ability to exploit different carbon sources. The ability to grow on different carbon sources gives an indication of whether particular enzyme classes are reduced in the mutant. WT, cga1 and the MAPK mutant chk1 were grown on minimal media containing pectin, carboxymethylcellulose (CMC), gelatin or casein (protein source) or maltose as sole carbon sources. Complete medium (CM) was used as a standard, since WT and both signaling mutants grow well and at an almost similar rate in this medium [39]. Indeed, after seven days of incubation on CM at room temperature in the light, all three strains grew at a similar rate, covering the standard $90 \mathrm{~mm}$ petri dishes (Figure 1). The growth of WT and mutants on minimal medium with the various specific carbon sources was significantly slower (Figure 1). cga1 showed similar colony size to WT when grown on pectin (for the first seven days), CMC and gelatin (after 13 days). After seven days on pectin, there was some deceleration in WT growth rate and, as a result, cga1 reached significantly $(\mathrm{P}<0.05)$
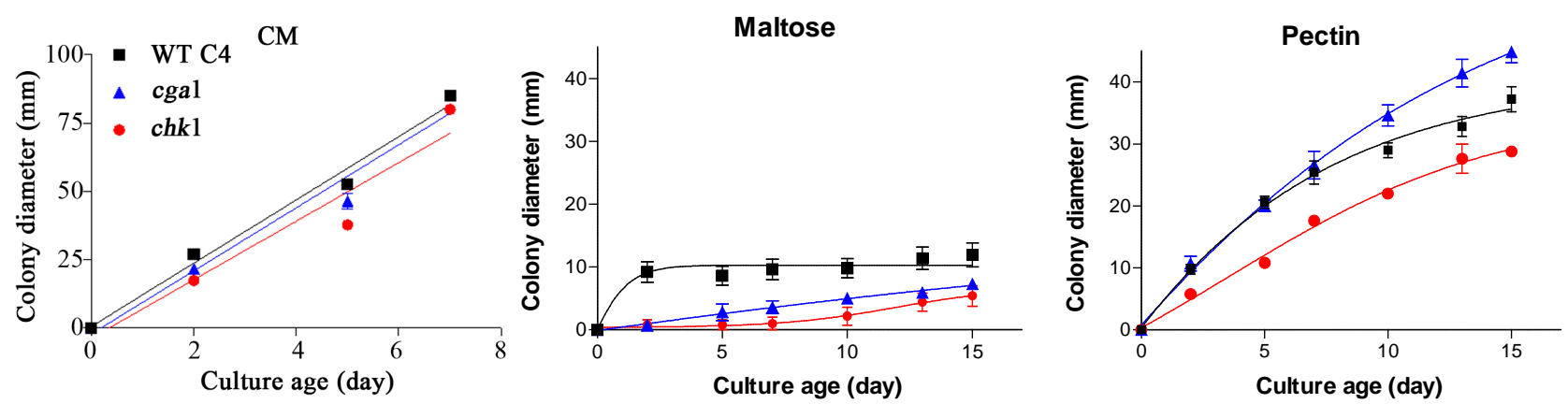

Gelatin
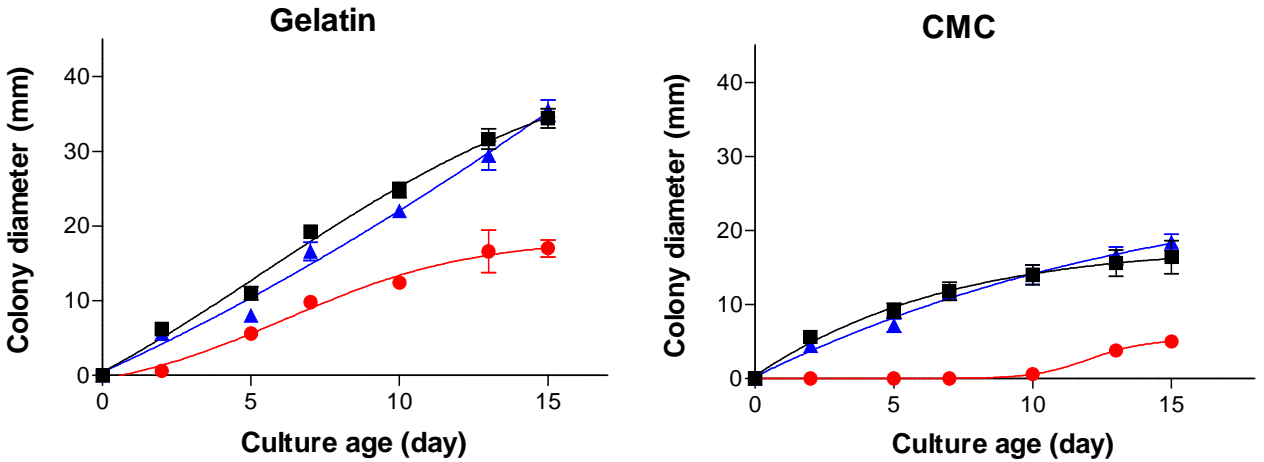

Figure 1. Growth rate of cga1 (G-protein $\alpha$ subunit disrupted mutant), chk1 (MAPK deficiency strain) and WT (C4) on different sole carbon sources. The fungi were grown on complete medium (CM), or minimal medium (without maltose) with $0.1 \%$ carboxymethylcellulose (CMC), gelatin, pectin or maltose as a sole carbon source, for 15 days at $30^{\circ} \mathrm{C}$ under continuous white light. Colony diameter was measured every 2 - 3 days. Values represent an average of 4 - 5 plates. Bars indicate standard error. 
larger colony size. Significant reduction in growth of cga1 in comparison to the WT was found only on maltose $(\mathrm{P}<0.01)$ and gelatin (between days $4-10, \mathrm{P}<0.05$ ) (Figure 1). chk1 grew very slowly on all minimal media, but grew almost like WT on complete medium. Interestingly, chk1 did not grow at all on CMC-containing medium for the first seven days (Figure 1). The results of specific staining tests for pectin degradation with ruthenium red and for CMC degradation with Congo red supported these conclusions: cga1 and WT have similar ability to degrade pectin and CMC while the chk1 mutant strains has reduced ability to degrade those carbon sources (Figure 2).

Examination of growth rate of these strains on the same media but with the addition of $0.1 \%$ maltose, the use of larger amounts of carbon sources (1\% of CMC and pectin instead of $0.1 \%$ ) and at a lower temperature $\left(25^{\circ} \mathrm{C}\right.$ instead of $\left.30^{\circ} \mathrm{C}\right)$ caused a significant elevation of the growth rate of all strains as expected due to the supplement of an available sugar for the first days of growth, but the fungus strains grew at the same pattern in all media (Figure 3). This indicates the elimination of the unique influence of each carbon source. On the pectin-containing media, there was an overall reduction in growth rate but the relation between strains was retained. Interestingly, under these conditions there was a higher growth rate of WT strains in comparison to cga1 mutant strains. One explanation for this may be that WT strains are more easily adapted to the alternative nutritional source after utilization of the maltose. Two more strains were tested under these conditions, cgb1 (G-protein $\beta$ subunit mutant) and cga1 cgb1 (G-protein $\alpha$ and $\beta$ subunits double mutant) (see Table 1). While $c g b 1$ showed a reduction in growth rate in comparison to WT but at a lesser severity than the cga1 strains, the double mutant had a growth rate similar to WT (Figure 3).

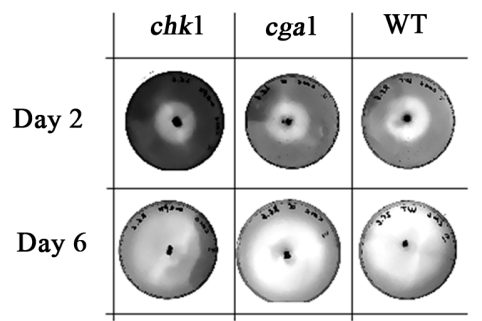

(a)

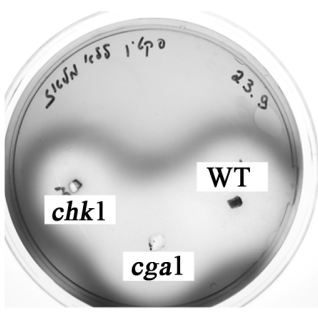

(b)
Figure 2. Staining test for chk1, cga1 and WT (C4) cultures on CMC (a) and pectin (b). Conditions as in Figure 1. Residual pectin in the plates was determined after 7 days growth by staining with $0.2 \%$ ruthenium red, and residual CMC was determined after 2 and 6 days by 1\% Congo red (according to Hagerma et al., 1985 [35]). The white halo is an area where the fungi have degraded the pectin or CMC in the medium.
The significant reduction in chk1 cultures on CMCcontaining medium encouraged us to examine further the role of the MAPK signaling hierarchy in the ability of the pathogen to degrade cellulose. In order to measure extracellular CMCase activity during the growth of $C$. heterostrophus on inductive medium containing CMC, a preliminary experiment was conducted. This preliminary experiment aimed at verifying that the amount of maltose in the medium would allow good recovery and initial growth of the fungus without interfering with the nutritional growth shift to CMC exploitation. This is especially important since uncontrolled concentrations of maltose may cause catabolic repression as reported for glucose [26]. In addition, this assay enables us to determine the growth day in which maximal yield of CMCase activity is measured. The preliminary time course measurements showed that after four days, the fungi exploited all the maltose in the medium and that a peak of CMCase activity was achieved at day 6 (Figure 4). This tendency was also measured for cga1 (data not shown). The sixth growth day was determined to be optimal for harvesting the cultures in order to determine CMCase activity and was used in the subsequent experiments.

Quantitative enzymatic assay for CMCase activity was carried out for the WT, chk1 and three additional mutant strains defective in cellulases genes, eg6f (endoglucanase disrupted mutant), eg6f chk1 double mutant and cbh7 (cellobiohydrolase disrupted mutant). Strains were grown in CMC or maltose shaking liquid culture and harvested on the sixth day of growth. The eg6f and the WT strains grew well on both media, while the chk1 and eg6f chk1 strains showed growth reduction in CMC medium (data not shown). The $c b h 7$ had a weak ability to grow on either media as well as on CM rich medium (data not shown). It is therefore likely that the $E G 6 F$ gene has no effect on CMCase activity, while CHK1 and $\mathrm{CBH} 7$ may be involved in CMCase secretion.

Indeed, extracellular enzymatic assays revealed a significant reduction in CMCase activity in the chk1, eg6f chk1 and cbh7 cultures in comparison to the WT or eg6f cultures, which showed similar activity (Figure 5(a)). It is clear from this result that disruption of the EG6F gene has no effect on CMCase activity and that $C H K 1$ and $C B H 7$ expressions induce CMCase activity. Evidence supporting this conclusion was accepted by northern blot analysis, indicating that eg6f is expressed in both CMC and maltose media by the WT strain (Figure 5(b)). Furthermore, disruption of $C H K 1$ abolished EG6F expression in the CMC medium and caused a significant reduction of its expression in the maltose medium, indicating that MAPK signaling controls the expression of this endoglucanase (Figure 5(b)). Determination of total extracellular protein concentrations revealed an induction of secreted protein levels in eg6f cultures and a reduction of these levels in the $c h k 1$ disrupted cultures (Figure 5(a), insert). 


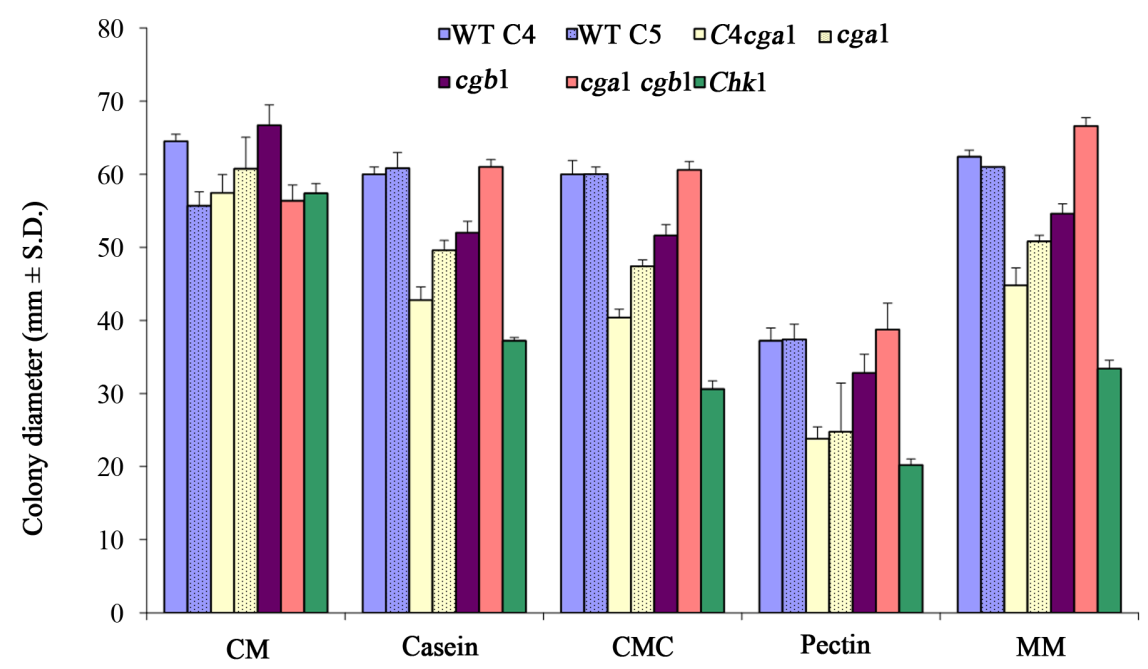

Figure 3. Growth rate of WT and signaling deficiency mutant strains on different carbon sources including an additional maltose. The fungi were grown on complete medium (CM), or minimal media (with $0.1 \%$ maltose) containing $1 \%$ carboxymethylcellulose (CMC), gelatin or pectin as a carbon source, or $12.5 \mathrm{ml} / \mathrm{L}$ fat-free milk as a casein source, for 4 days at $25^{\circ} \mathrm{C}$ under continuous white light. $c g b 1-\mathrm{G}$-protein $\beta$ subunit mutant, cga 1 cgb1-G-protein $\alpha$ and $\beta$ subunits double mutant, MM-minimal medium containing $1 \%$ maltose without any additional carbon source. All other abbreviations as in Figure 1. Values represent a colony diameter average of five plates. Bars indicate standard deviation.

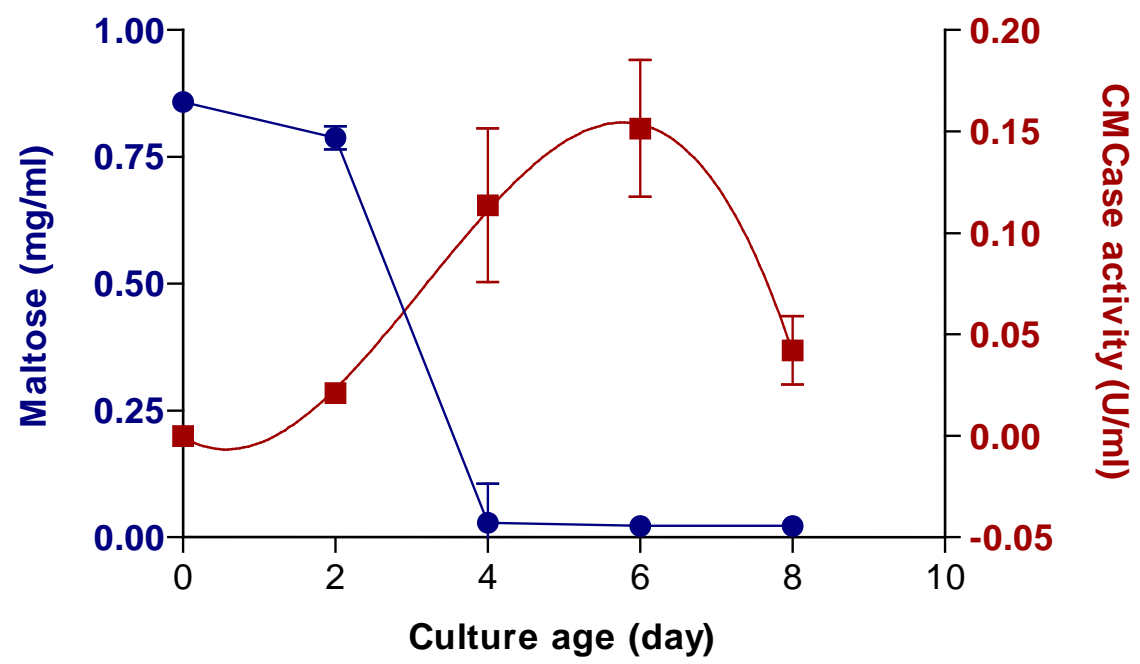

Figure 4. CMCase (Carboxymethylcellulose degrading enzymes) activity and maltose concentrations during the growth of $C$. heterostrophus. WT C4 strain was pre-grown for 8 days on CM agar plates at room temperature under UVA-enriched white light. Six mm (in diameter) agar disks were cut from the margins of the colony and transferred to a 50 $\mathrm{ml}$ polycarbonate screw-capped test tube containing $20 \mathrm{ml}$ minimal medium with $0.1 \%$ CMC and $0.1 \%$ maltose. The cultures were incubated diagonally in a rotary shaker at 210 - $230 \mathrm{rpm}$ and at a temperature of $30^{\circ} \mathrm{C}$ under continuous fluorescent white light. Values represent an average of five measurements. Bars indicate standard error.

Repeating this experiment with an elevation in CMC concentrations from $0.1 \%$ to $1 \%$ (W/V) (Table 2) caused a less significant difference between the WT and chk1 strains although CMCase activity levels in the chk1 cul- tures remain low in comparison to the WT and all other strains. chk1 cultures also had a minor reduction in extracellular protein levels (Table 2). All other strains showed similar CMCase activity and protein levels. 
(a)

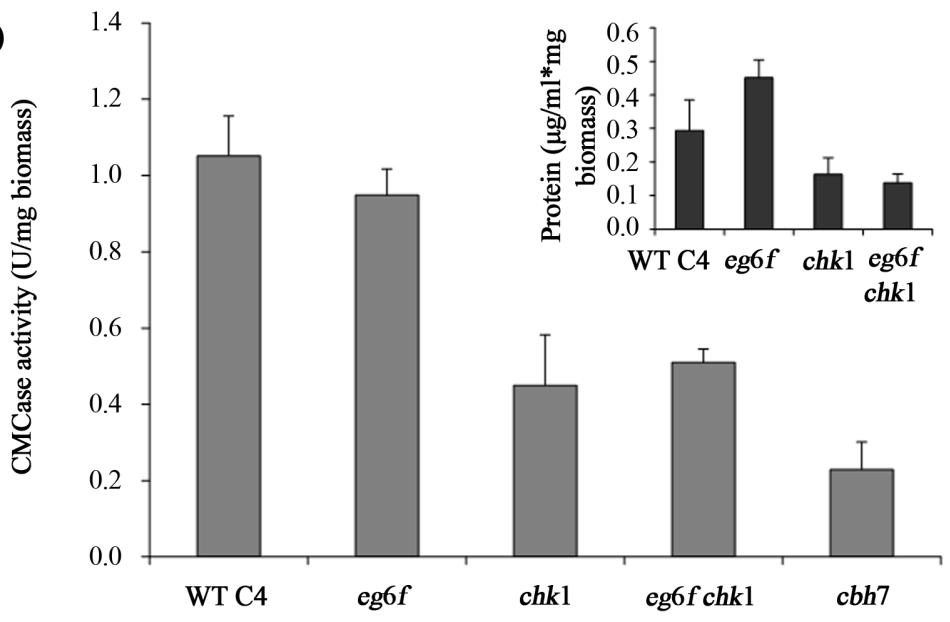

(b)

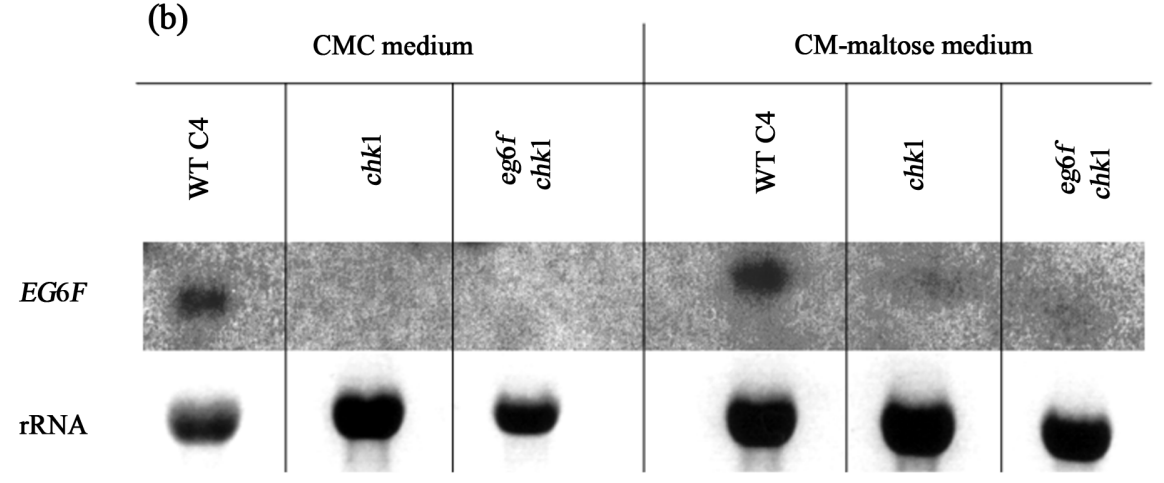

Figure 5. CMCase extracellular activity determination of C. heterostrophus strains. (a) Extracellular CMCase enzymatic activity was measured for liquid cultures grown for 6 days on $0.1 \%$ CMC and $0.1 \%$ maltose containing minimal medium. Cultures were grown in continuous white light at $30^{\circ} \mathrm{C}$ in a rotary shaker (210 rpm). Insert shows the extracellular protein levels. Values represent an average of six independent replicates. Bars indicate standard deviation; (b) Northern blot analysis of EG6F (endoglucanase) gene expression in WT C4, chk1 and eg6f chk1 strains that were grown on CMC or CM-maltose (Complete medium with maltose) liquid medium. Sample strains from the cultures used for activity assay were tested against EG6F probe, as described before [34].

\section{DISCUSSION}

Plant parasitic fungi have conquered the living plant as a copious source of nutrients. For successful parasitism, a crucial step is penetration. In order to overcome the various barriers present in leaves, stems, or roots, fungi have evolved astonishingly diverse invasion strategies (reviewed by [1]). The role of fungal-secreted extracellular enzymes in diseases has been postulated to include the penetration of plant cell walls, release of nutrients that can be assimilated for growth and the elicitation of defense responses [40]. Penetration of pathogens into parenchymatous tissues requires the breakdown of the cell walls, which consist of cellulose, pectins, hemicelluloses and structural proteins [41]. Initially, the pathogen encounters the waxy cuticle. In addition, complete plant tissue disintegration involves the breakdown of lignin. The degradation of each of these substances is brought about by the action of one or more sets of extracellular lytic enzymes [42]. These enzymes comprise lipases, pectinases, cellulases, hemicellulases and proteases. To date, only a few studies have examined the influence of the $G$ protein or MAPK signaling on extracellular enzyme secretion.

Wang and Nuss [29] first reported that the induction of $C H B-1$, a cellobiohydrolase gene from Cryphonectria parasitica, is mediated through a G-protein $\alpha$ subunit linked signal transduction pathway shown earlier to be required for fungal pathogenesis [43]. In saprophytic and pathogenic fungi, it is known that extracellular glycan hydrolases are induced by their substrate and repressed by glucose at the level of gene expression (reviewed by 
Table 2. CMCase extracellular activity determination of $C$. heterostrophus strains under the influence of redundant substrate ${ }^{\mathrm{a}}$.

\begin{tabular}{ccccc}
\hline Strain & CMCase activity (U/mg biomass) & \multicolumn{2}{c}{ Protein $(\mathbf{m g} / \mathbf{m l})$} \\
\hline & Average & S.D. & Average & S.D. \\
\hline WT C4 & 4.59 & 0.15 & 14.95 & 0.51 \\
WT C5 & 4.20 & 0.22 & 14.32 & 0.27 \\
C4cga 1 & 3.94 & 0.12 & 16.02 & 0.86 \\
cga1 & 4.34 & 0.47 & 15.19 & 0.57 \\
cgb1 & 4.96 & 0.17 & 14.82 & 0.71 \\
cga 1 cgb1 & 4.17 & 0.06 & 13.71 & 0.94 \\
chk1 & 3.81 & 0.26 & 11.85 & 1.26 \\
\hline
\end{tabular}

${ }^{a}$ Extracellular CMCase enzymatic activity was measured for liquid cultures grown on $1 \%$ CMC and $0.1 \%$ maltose containing minimal medium. All other conditions as in Figure 5. Values represent an average of 3 and 5 independent replicates of two separate experiments.

[26]). Since glucose acts via Gpr1 (the S. cerevisae $\mathrm{G}$-protein-coupled receptor) and $\mathrm{G} \alpha(\mathrm{Gpa} 2)$ to trigger a rapid and transient increase in intracellular cAMP levels (reviewed by [44]), it is possible that G-protein associated signal transduction triggered by glucose may influence extracellular enzyme secretion.

In Cochliobolus heterostrophus, cga1 was previously shown to have increased ability to infect detached senesce leaves that may provide a more readily available nutrient source [38]. We therefore tested whether in axenic culture, the WT, cga1 and other signal transduction disrupted mutant strains are impaired in their ability to produce enzymes or to use a particular carbon source. We showed that cga1 grew at a rate similar to WT on pectin or CMC, whereas chk1 showed an overall weakened ability to grow on all minimal media (Figures 1 and 2). Although no significant differences were found in CMCase activity between cga1 and the WT strain, we found that both strains, on medium containing maltose and CMC, showed initial CMCase activity only after exploitation of the maltose in the medium (exemplify for the WT in Figure 4). It seems that a maltose nutrient signal serves for CMCase repression as long as maltose is present in the medium. Interestingly, cga1 grew significantly slower on maltose (Figure 1). One explanation may be that poor growth conditions emphasized some overall weakness of the cga1 mutant.

Another noticeable result here is the normal growth rate (WT growth rate) of the double mutant of $\mathrm{G}$ protein alpha and beta subunit genes on all minimal media (Figure 3). It was previously demonstrated that the double mutant (cga1 cgb1) exhibits some phenotypical behaviors that are influenced by the two subunits separately [39]. For example, it is sensitive to $\mathrm{KCl}$ like cga1 and resistant to sorbitol like cgb1. This indicates that some traits are controlled by a sole subunit. Other traits, like the inability to produce spores, are altered synergistically due to double disruption of the $\mathrm{G} \alpha$ and $\mathrm{G} \beta \gamma$ subunits, indicating the existence of a common control mechanism. The question as to why the disruption of the single $\mathrm{G}$ protein alpha or beta subunit genes led to a reduced capability to maintain normal growth on minimal media, while the disruption of both genes overcomes this weakness, must still be addressed.

In trying to answer this question, the possibility should be taken into consideration that both subunits act on each other to maintain normal activity and that loss of either subunit results in destabilization of the heterotrimer, so that the entire $G$ protein is defective in either mutant. There is evidence for this from studies in other fungi [4547]. For example, Segers and Nuss [30] noted that mutations in the G-protein subunits in Cryphonectria parasitica can have a dramatic effect on posttranscriptional accumulation of their presumptive G-protein partners, although no significant alteration in transcript accumulation was noted [46]. In particular, deletion of the $\mathrm{G} \alpha$ subunit $(\Delta c p g-1)$, and even more, constitutively activated $\mathrm{G} \alpha(c p g-1-Q L)$, or disruption of a regulator of G-protein signaling proteins ( $\Delta$ cprgs- 1 ) resulted in severe posttranscriptional reduction of $\mathrm{G} \alpha$ and $\mathrm{G} \beta$ subunit levels. In correlation with this, disruption of $\mathrm{G} \beta(\Delta c p g b-1)$ also led to reduced protein levels of both subunits [46]. Similar observations were reported for $N$. crassa [48].

Remarkably, chk1 failed to achieve the WT (and cga1) growth rate on CMC and did not grow at all for the first seven days of culture. An enzymatic activity test for CMCase revealed that this strain significantly reduced CMCase extracellular activity in 0.1\% CMC containing media whereas cga1 showed similar activity to that of the WT strain under the same conditions. Supporting this conclusion is the finding that a cellobiohydrolase mutant (cbh7) had a similar growth pattern on CMC and CMCase activity to the chk1 mutant, which may indicate that both mutants suffer from the same weakness. Indeed, the CHK1 (MAPK) pathway modulates the expression of two cellulase genes ([34], Figure 5). Gronover et al. [30] showed that a null mutant in $B C G 1$, a G-protein $\alpha$ subunit gene of the gray mold fungus Botrytis cinerea, differs in colony morphology from the WT strain, does not secrete extracellular proteases, and shows clearly reduced pathogenicity on bean and tomato. Here, we measured the ability of cga1 to grow on gelatin as protein sources in comparison to WT. There was no constant difference between the two strains, and cga1 was able to reach the WT levels of growth on this medium.

\section{CONCLUSION}

In conclusion, it appears that cga1 differs from WT only 
under minor poor conditions (as exemplified by maltose) in contrast to $c h k 1$, which has decreased ability to use several carbon sources and therefore may be defective in the production of several secreted enzymes. Thus, signal transduction via the MAPK pathway has an influence on the expression of genes associated with extracellular enzyme secretion. The mechanism of this regulation remains to be revealed

\section{ACKNOWLEDGEMENTS}

I would like to thank Dr. Benjamin A. Horwitz (Technion-Israel Institute of Technology, Israel) for his guidance and very helpful advices, Ella Chrysler (Technion-Israel Institute of Technology, Israel) for her technical assistance, Dr. Sophie Lev for her many helpful suggestions and Dr. B. Gillian Turgeon for the C4cga1 strain.

\section{REFERENCES}

[1] Mendgen, K., Hahn, M. and Deising, H. (1996) Morphogenesis and mechanisms of penetration by plant pathogenic fungi. Annual Review of Phytopathology, 34, 367386. http://dx.doi.org/10.1146/annurev.phyto.34.1.367

[2] Hsu, S.C., TerBush, D., Abraham, M. and Guo W. (2004) The exocyst complex in polarized exocytosis. International Review of Cytology, 233, 243-265. http://dx.doi.org/10.1016/S0074-7696(04)33006-8

[3] Nickel, W. (2005) Unconventional secretory routes: Direct protein export across the plasma membrane of mammalian cells. Traffic, 6, 607-614. http://dx.doi.org/10.1111/j.1600-0854.2005.00302.x

[4] Carvalho, C.M., Aires-Barros, M.R. and Cabral, J.M. (1999) Cutinase: From molecular level to bioprocess development. Biotechnology and Bioengineering, 66, 17-34. http://dx.doi.org/10.1002/(SICI)1097-0290(1999)66:1<17 :AID-BIT2>3.0.CO;2-F

[5] Kolattukudy, P.E., Rogers, L.M., Li, D., Hwang, C.S. and Flaishman, M.A. (1995) Surface signaling in pathogenesis. Proceedings of the National Academy of Sciences of the United States of America, 92, 4080-4087. http://dx.doi.org/10.1073/pnas.92.10.4080

[6] Degani, O., Gepstein, S. and Dosoretz, C.G. (2002) Potential use of cutinase in enzymatic scouring of cotton fiber cuticle. Applied Biochemistry and Biotechnology, 102103, 277-289.

[7] Degani, O., Gepstein, S. and Dosoretz, C.G. (2004) A new method for measuring scouring efficiency of natural fibers based on the cellulose-binding domain-beta-glucuronidase fused protein. Journal of Biotechnology, 107, 265-273. http://dx.doi.org/10.1016/j.jbiotec.2003.10.015

[8] Deising, H., Nicholson, R.L., Haug, M., Howard, R.J. and Mendgen, K. (1992) Adhesion pad formation and the involvement of cutinase and esterases in the attachment of uredospores to the host cuticle. Plant Cell, 4, 1101-1111.

[9] Kolattukudy, P.E. and Crawford, M.S. (1987) The role of polymer degrading enzymes in fungal pathogenesis. Springer, Heidelberg/Tokyo.
[10] Caprari, C., Bergmann, C., Migheli, Q., Salvi, G., Albersheim, P., Darvill, A, Cervone, F. and De Lorenzo, G. (1993) Fusarium moniliforme secretes four endopolygalacturonases derived from a single gene product. Physiological and Molecular Plant Pathology, 43, 453-462. http://dx.doi.org/10.1006/pmpp.1993.1073

[11] Herbert, C., Jacquet, C., Borel, C., Esquerre-Tugaye, M.T. and Dumas, B. (2002) A cis-acting sequence homologous to the yeast filamentation and invasion response element regulates expression of a pectinase gene from the bean pathogen Colletotrichum lindemuthianum. The Journal of Biological Chemistry, 277, 29125-29131. http://dx.doi.org/10.1074/jbc.M201489200

[12] Ilmen, M., Saloheimo, A., Onnela, M.L. and Penttila, M.E. (1997) Regulation of cellulase gene expression in the filamentous fungus Trichoderma reesei. Applied and Environmental Microbiology, 63, 1298-1306.

[13] Zeilinger, S., Mach, R.L. and Kubicek, C.P. (1998) Two adjacent protein binding motifs in the cbh2 (cellobiohydrolase II-encoding) promoter of the fungus Hypocrea jecorina (Trichoderma reesei) cooperate in the induction by cellulose. The Journal of Biological Chemistry, 273, 34463-34471. http://dx.doi.org/10.1074/jbc.273.51.34463

[14] Bajar, A., Podila, G.K. and Kolattukudy, P.E. (1991) Identification of a fungal cutinase promoter that is inducible by a plant signal via a phosphorylated trans-acting factor. Proceedings of the National Academy of Sciences of the United States of America, 88, 8208-8212. http://dx.doi.org/10.1073/pnas.88.18.8208

[15] Kamper, J.T., Kamper, U., Rogers, L.M. and Kolattukudy, P.E. (1994) Identification of regulatory elements in the cutinase promoter from Fusarium solani $f$. sp. pisi (Nectria haematococca). The Journal of Biological Chemistry, 269, 9195-9204.

[16] De Lorenzo, G. and Ferrari, S. (2002) Polygalacturonaseinhibiting proteins in defense against phytopathogenic fungi. Current Opinion in Plant Biology, 5, 295-299. http://dx.doi.org/10.1016/S1369-5266(02)00271-6

[17] Gielkens, M.M., Dekkers, E., Visser, J. and de Graaff, L.H. (1999) Two cellobiohydrolase-encoding genes from Aspergillus niger require D-xylose and the xylanolytic transcriptional activator $\mathrm{X} \ln \mathrm{R}$ for their expression. Applied and Environmental Microbiology, 65, 4340-4345.

[18] Hasper, A.A., Dekkers, E., van Mil, M., van de Vondervoort, P.J. and de Graaff, L.H. (2002) EglC, a new endoglucanase from Aspergillus niger with major activity towards xyloglucan. Applied and Environmental Microbiology, 68, 1556-1560. http://dx.doi.org/10.1128/AEM.68.4.1556-1560.2002

[19] van Peij, N.N., Gielkens, M.M., de Vries, R.P., Visser, J. and de Graaff, L.H. (1998) The transcriptional activator $\mathrm{X} \operatorname{lnR}$ regulates both xylanolytic and endoglucanase gene expression in Aspergillus niger. Applied and Environmental Microbiology, 64, 3615-3619.

[20] Kubo, Y., Tsuda, M., Furusawa, I. and Shishiyama, J. (1989) Genetic analysis of genes involved in melanin biosynthesis of Cochliobolus miyabeanus. Experimental Mycology, 13, 77-84.

[21] Apel, P.C., Panaccione, D.G., Holden, F.R. and Walton, 
J.D. (1993) Cloning and targeted gene disruption of XYL1, a beta 1,4-xylanase gene from the maize pathogen Cochliobolus carbonum. Molecular Plant-Microbe Interactions, 6, 467-473.

http://dx.doi.org/10.1094/MPMI-6-467

[22] Schaeffer, H.J., Leykam, J. and Walton, J.D. (1994) Cloning and targeted gene disruption of EXG1, encoding exo-beta 1, 3-glucanase, in the phytopathogenic fungus Cochliobolus carbonum. Applied and Environmental Microbiology, 60, 594-598.

[23] Scott-Craig, J.S., Panaccione, D.G., Cervone, F. and Walton, J.D. (1990) Endopolygalacturonase is not required for pathogenicity of Cochliobolus carbonum on maize. Plant Cell, 2, 1191-1200.

[24] Sposato, P., Ahn, J.H. and Walton, J.D. (1995) Characterization and disruption of a gene in the maize pathogen Cochliobolus carbonum encoding a cellulase lacking a cellulose binding domain and hinge region. Molecular Plant-Microbe Interactions, 8, 602-609. http://dx.doi.org/10.1094/MPMI-8-0602

[25] Bowen, J.K., Templeton, M.D., Sharrock, K.R., Crowhurst, R.N. and Rikkerink, E.H. (1995) Gene inactivation in the plant pathogen Glomerella cingulata: three strategies for the disruption of the pectin lyase gene pnlA. Molecular Genetics and Genomics, 246, 196-205. http://dx.doi.org/10.1007/BF00294682

[26] Ronne, H. (1995) Glucose repression in fungi. Trends in Genetics, 11, 12-17. http://dx.doi.org/10.1016/S0168-9525(00)88980-5

[27] de Vries, R.P., Visser, J. and de Graaff, L.H. (1999) CreA modulates the XlnR-induced expression on xylose of Aspergillus niger genes involved in xylan degradation. Research in Microbiology, 150, 281-285. http://dx.doi.org/10.1016/S0168-9525(00)88980-5

[28] Orejas, M., MacCabe, A.P., Perez Gonzalez, J.A., Kumar, S. and Ramon, D. (1999) Carbon catabolite repression of the Aspergillus nidulans xlnA gene. Molecular Microbiology, Vol. 31, 177-184. http://dx.doi.org/10.1046/j.1365-2958.1999.01157.x

[29] Wang, P. and Nuss, D.L. (1995) Induction of a Cryphonectria parasitica cellobiohydrolase I gene is suppressed by hypovirus infection and regulated by a GTP-bindingprotein-linked signaling pathway involved in fungal pathogenesis. Proceedings of the National Academy of Sciences of the United States of America, 92, 11529-11533. http://dx.doi.org/10.1073/pnas.92.25.11529

[30] Gronover, C.S., Kasulke, D., Tudzynski, P. and Tudzyns$\mathrm{ki}, \mathrm{B}$. (2001) The role of $\mathrm{G}$ protein alpha subunits in the infection process of the gray mold fungus Botrytis cinerea. Molecular Plant-Microbe Interactions, 14, 12931302. http://dx.doi.org/10.1094/MPMI.2001.14.11.1293

[31] Madhani, H.D., Galitski, T., Lander, E.S. and Fink, G.R. (1999) Effectors of a developmental mitogen-activated protein kinase cascade revealed by expression signatures of signaling mutants. Proceedings of the National Academy of Sciences of the United States of America, 96, 1253012535. http://dx.doi.org/10.1073/pnas.96.22.12530

[32] Roberts, C.J., Nelson, B., Marton, M.J., Stoughton, R., Meyer, M.R., Bennett, H.A., He, Y.D., Dai, H., Walker,
W.L., Hughes, T.R., Tyers, M., Boone, C. and Friend, S.H. (2000) Signaling and circuitry of multiple MAPK pathways revealed by a matrix of global gene expression profiles. Science, 287, 873-880.

http://dx.doi.org/10.1126/science.287.5454.873

[33] Dawe, A.L., Segers, G.C., Allen, T.D., McMains, V.C. and Nuss, D.L. (2004) Microarray analysis of Cryphonectria parasitica Galpha- and Gbetagamma-signalling pathways reveals extensive modulation by hypovirus infection. $\mathrm{Mi}$ crobiology, 150, 4033-4043.

[34] Lev, S. and Horwitz, B.A. (2003) A mitogen-activated protein kinase pathway modulates the expression of two cellulase genes in Cochliobolus heterostrophus during plant infection. Plant Cell, 15, 835-844. http://dx.doi.org/10.1105/tpc.010546

[35] Hagerman, A.E., Blau, D.M. and McClure, A.L. (1985) Plate assay for determining the time of production of protease, cellulase, and pectinases by germinating fungal spores. Analytical Biochemistry, 151, 334-342. http://dx.doi.org/10.1016/0003-2697(85)90184-8

[36] Leach, J., Lang, B. and Yoder, O.C. (1982) Methods for selection of mutants and in vitro culture of Cochliobolus heterostrophus. Journal of General Microbiology, 128, 1719-1729.

[37] Miller, G.L. (1959) Use of dinitrosalicylic acid reagent for determination of reducing sugar. Analytical Chemistry, 31, 426-428. http://dx.doi.org/10.1021/ac60147a030

[38] Degani, O., Maor, R., Hadar, R., Sharon, A. and Horwitz, B.A. (2004) Host physiology and pathogenic variation of Cochliobolus heterostrophus strains with mutations in the G protein alpha subunit, CGA1. Applied and Environmental Microbiology, 70, 5005-5009. http://dx.doi.org/10.1128/AEM.70.8.5005-5009.2004

[39] Degani, O. (2013) Cochliobolus heterostrophus G-protein alpha and beta subunit double mutant reveals shared and distinct roles in development and virulence. Physiological and Molecular Plant Pathology, 82, 35-45. http://dx.doi.org/10.1016/j.pmpp.2013.01.004

[40] Walton, J.D. (1994) Deconstructing the cell wall. Plant Physiology, 104, 1113-1118.

[41] Agrios, G.N. (2005) Plant pathology. Academic Press Inc., London.

[42] Kolattukudy, P.E. (1985) Enzymatic penetration of the plant cuticle by fungal pathogens. Annual Review of Phytopathology, 23, 223-250. http://dx.doi.org/10.1146/annurev.py.23.090185.001255

[43] Choi, G.H., Chen, B. and Nuss, D.L. (1995) Virus-mediated or transgenic suppression of a G-protein alpha subunit and attenuation of fungal virulence. Proceedings of the National Academy of Sciences of the United States of America, 92, 305-309. http://dx.doi.org/10.1073/pnas.92.1.305

[44] Lengeler, K.B., Davidson, R.C., D’Souza, C., Harashima, T., Shen, W.C., Wang, P., Pan, X., Waugh, M. and Heitman, J. (2000) Signal transduction cascades regulating fungal development and virulence. Microbiology and Molecular Biology Reviews, 64, 746-785. http://dx.doi.org/10.1128/MMBR.64.4.746-785.2000 
[45] Parsley, T.B., Segers, G.C., Nuss, D.L. and Dawe, A.L. (2003) Analysis of altered G-protein subunit accumulation in Cryphonectria parasitica reveals a third Galpha homologue. Current Genetics, 43, 24-33.

[46] Segers, G.C. and Nuss, D.L. (2003) Constitutively activated Galpha negatively regulates virulence, reproduction and hydrophobin gene expression in the chestnut blight fungus Cryphonectria parasitica. Fungal Genetics and Biology, 38, 198-208.

http://dx.doi.org/10.1016/S1087-1845(02)00534-0

[47] Segers, G.C., Regier, J.C. and Nuss, D.L. (2004) Evidence for a role of the regulator of G-protein signaling protein CPRGS-1 in $\mathrm{G} \alpha$ subunit CPG-1-mediated regulation of fungal virulence, conidiation, and hydrophobin synthesis in the chestnut blight fungus Cryphonectria parasitica. Eukaryotic Cell, 3, 1454-1463. http://dx.doi.org/10.1128/EC.3.6.1454-1463.2004

[48] Kays, A.M. and Borkovich, K.A. (2004) Severe impairment of growth and differentiation in a Neurospora crassa mutant lacking all heterotrimeric $\mathrm{G} \alpha$ proteins. Genetics, 166, 1229-1240.

http://dx.doi.org/10.1534/genetics.166.3.1229 